\title{
The Influence of Teachers' Appearance in the Process of Teaching on the Teaching Effect
}

\author{
Yu-ling ZHAO ${ }^{1}$, \\ ${ }^{1}$ Northeast Dianli University, \\ Jilin 132012, Jilin, China
}

\author{
Zhuo ZHANG* , \\ ${ }^{2}$ China-Japan Union Hospital, Jilin University, \\ Changchun 130033, Jilin, China \\ ${ }^{*}$ Corresponding author
}

\author{
Chang-xia $\mathrm{CHENG}^{2}$ \\ ${ }^{2}$ China-Japan Union Hospital, Jilin University, \\ Changchun 130033, Jilin, China
}

\begin{abstract}
Along with the reform of the times, people hold different pursuits and aesthetic views about clothing, and naturally their understanding of clothing is different. Teachers must always be a good model of virtue for students. There is no exception to appearance, because a teacher must be addressed appropriately and tastefully and accompanied by graceful manner and genial language. In general, the promotion of the moral education for students is influenced by every word and action of a teacher. The teaching effect and prestige of a teacher can be better improved, if his or her appearance is rigorous and modest and personal identity and personality are manifested in clothing.
\end{abstract}

Keywords: Teachers; Appearance; Teaching Effect

\section{Introduction}

As an old Chinese proverb goes, clothing makes a man just as a saddle makes a horse, or fine feathers make fine birds. A teacher needs to pay attention to his or her appearance in all aspects if he or she expects to establish a good image. From clothing to headgear, makeup, decorations, manners and even nails, every aspect needs to be concerned, among which clothing is the most important because it shows a teacher's attitude toward work and life.

\section{The importance of appearance}

In the civilization history of human development, the development of clothing was always equipped with its social functions, because it was a kind of expression to personal lifestyle and values. Clothing is a visual tool and can be used by man to achieve his own purpose, and a man's overall display - clothes, body, face, and attitude help open a door to triumph, and a man's prestige, credibility, and popularity can be transferred by your appearance to the world, said the famous American image design master Robert Pound. As an old Chinese proverb goes, clothes make a man just as a saddle makes a horse. This just states the importance of clothes for people. Judging people solely by their appearance and clothes is inadvisable. However, the results of the surveys about the image of people show that $76 \%$ of people are still easy to judge a person by his or her clothes and according decide to take a corresponding attitude toward communication.

\section{Teacher's self-confidence and student's influence and appeal can be improved by teacher's clothes}

In terms of education scenes, teacher's clothes are not irrelevant with the development of students. On the contrary, student's attitude toward teacher and the relationship with the teacher has a close tie with teacher's clothes. The attitudes of the students in different kinds of schools toward teacher's clothes, hairstyle and 
other external elements were investigated, finding the appearance of teachers were more frequently concerned by the students who were more mature. The preference of students for teachers depends on not only teachers' teaching competence and learned knowledge, but also is significantly related to the external image reflected from teacher's clothes.

The biggest function of a teacher's clothes is to improve his or her own self-confidence and influence on student, but not to dress up him or her beautifully using clothing. In a general way, the different clothing and makeup of teachers can show different information to students and produce different emotional responses to students.

First, a teacher's living habit, lift styles and spirit of self-confidence can be embodied in clothes. From neat clothes, simple pattern, reasonable color collocation, and shirt replaced every day, a teacher's orderly affairs handling, concise, capable and experienced behaviors, and good living habits of paying attention to sanitation and health are often reflected. However, a teacher, whose clothing styles and patterns are complex, always let people think of heavy-headed and burdensome behaviors; a teacher, whose clothing color collocation is greatly different in daily times, often let people feel inharmonious, easy to change, and difficult to communicate.

Second, clothes are external symbols to a teacher's emotion, hobbies and interests, and traits of character, while the mental state of students in the process of educational activities is influenced by a teacher's emotion.

Third, the role difference between teachers in educational activities is reflected in clothes, and also the teaching effect is affected by clothes. In the sportswear of PE teachers, the beauty of health and sports is displayed. A PE teacher's western suits and leather shoes in sports class does not fit with his professional role.

\section{Teacher's appearance and classroom teaching}

Human communication is a combination of language communication with nonverbal communication. In addition to using language for communicating and exchanging ideas and transferring information, some nonverbal means are often used by human. Clothes refer to the clothes and makeup of people, which is one of the important nonverbal means. Some scholars in the west think that the nonverbal communication in class often plays a greater role than formal teaching in the learning of students. Studies proved that the relationship between teachers and students would be improved if how to more effectively use nonverbal communication in class was learned well by teachers, and simultaneously students' cognitive competence and learning efficiency will increase. Now that such a big communication role is contained in clothing language, how does a teacher dress up himself or herself to better meet the needs of classroom teaching? A "naturally coordination" principle is raised by clothes experts. First, clothes must be coordinated with the self-characteristics of a person. Everyone in the world is a natural person, but also a social person. To be well dressed, he or she must have a comprehensive, correct knowledge of his or her own characteristics. Generally speaking, a person dressed orderly works earnestly; a person dressed plainly is hardworking and thrifty; a person dressed obsoletely and monotonously is conservative; a person dressed brightly in color is lively; a person dressed gloomily is cool, and so on. Every one's clothing is necessarily consistent with his social role, and appropriate clothing can help become successful in the career. Clothes must be correspondingly changed when a person's identity and status alter. The clothes of kindergarten teachers are definitely different from middle school teachers though they are occupied in teaching activities. Second, dressing must be correct under different situation. Generally, clothes must be harmonious with time, place, occasion, coordinated communication 
objects, and communicative purpose. Time mainly includes era and season. Clothes need to demonstrate individual characters and abide by the trend of the times. Too much emphasis on individual characters and pursuit of novelty is not advisable if social norm are ignored.

\section{The details of teacher clothes}

Generally speaking, teacher's clothing should be simple, solemn, lively and decent, and conform to the teachers' professional norms. However, students' attitude towards a teacher is affected by many details of the teacher's clothes. In educational scenes, what details in teachers' clothes are necessary to focus on?

\subsection{Text and graphic information on teachers' clothes}

The information transferred by clothes should always be positive and consistent with the self-style. Text and graphics play an adornment effect on clothes. Cultural clothes refer to those clothes on which some words or patterns with specific meanings are designed. In general, the meaning of Chinese characters on clothes is more stressed by people. However, the meanings of foreign words on clothes must be understood clearly, and otherwise troubles may occur. For example, the lesson from Xiang LI's "vamp t-shirt" is that the meaning of foreign language information on clothes should never be ignored. Therefore, young teachers have to pay attention to the new clothes they are going to buy. It is suggested that this detail should never be ignored if cultural clothes will be bought by people.

\subsection{Teacher's clothing style}

In the school life, teacher's clothes are supposed to complete and not arbitrarily to expose some private parts of body. Being in rags is not in conformity with a teacher's professional role, and clothes baring midriff or designed for sex appeal are not suitable for a teacher to wear in school. Male teachers should not wear suit and shorts in summer class.

\subsection{Teacher's clothing structural integrity}

Clothes' breakage, buttons' absence, and underwear exposure are details very easy to ignore. A teacher has to change damaged clothes in time, checks whether all buttons exist, and makes sure shirt or underwear not exposed outside the coats with back vents.

\subsection{Clean clothes}

The external image of teacher will be damaged by obvious oil contamination, massive black spots on tops, stains on tie, spots and damages on leader and cuff.

\subsection{Clothes color}

Teachers' clothes must be concise, bright and reasonable color without exaggeration. To choose the color, the facial skin must be considered. Cool clothes are less worn as far as possible, because exciting feeling can't be generated by gray and cool clothes to students. The adornments matching clothes should not be too much, complex, or large. Female teachers instead can't let the effect of adornments if a piece of too big shawl is worn by them. Male teachers are difficult to produce a feeling of kindness to students if a piece of bulky necklace is worn.

\section{Conclusion}

From the above analysis, it is concluded that a teacher's clothes is worn not only for themselves. It is not hard to imagine the meanings of "serve as role models" and "teach by personal example as well as verbal instruction". In solemn class, what a "personal role" effect will be produced from teachers whose clothes are exaggerated and exposed to the students whose body and mind are not mature? In fact, based on this awareness, people will say, "A teacher's clothes are also parts of educational environment". The reason why the beauty of a person's appearance is attractive is that it covers all the beauty of a person as social man and dynamically combines man's external and internal beauty together. Clothes not only let people enjoy from a visual sense, but also show 
respect to a person's personality. Paying attention to the beauty of appearance is not merely an issue concerning about image, but also a silent language.

\section{References}

[1] Li MIAO, Wenge WANG. Clothing Psychology [M]. Beijing: China Textile Publishing House, 1997
[2] Nihalani ND, Kunwar A, Stauer J, et al. How Should Psychiatrists-dress-A Server [J]. Community Mental Health Journal, 2006, 42 (3): 291-302.

[3] Major K,Hayasse Y, Balderrama D, et al. Attitudes Regarding Surgeons Attire [J]. The American Journal of Surgery, 2005, 190 (1): 103-106. 